\title{
Urubus, gambás e muriçocas no Maranhão segundo dados do
} ALiMA

\author{
Black vultures, opossums and mosquitoes in Maranhão according to data from
}

ALiMA

Gabriel Pereira CASTRO*

Universidade Federal do Maranhão (UFMA)

Conceição de Maria de Araujo RAMOS ${ }^{* *}$

Universidade Federal do Maranhão (UFMA)

RESUMO: O presente trabalho enfoca a variação denominativa concernente ao léxico da fauna no Maranhão, mais particularmente as variações referentes às formas urubu, gambá e muriçoca, com base no corpus constituído para elaboração do Atlas Linguístico do Maranhão (ALiMA). Tem como objetivos examinar a distribuição diatópica das variantes para essas formas, no Estado, e investigar quais fatores extralinguísticos condicionam essa variação. Os pressupostos teórico-metodológicos da Geolinguística/Dialetologia (FERREIRA; CARDOSO (1994) e CARDOSO (2010)), da Sociolinguística (CALLOU (2010)) e da Lexicologia (BIDERMAN (2001) e KRIEGER (2006 e 2014)) fundamentam o estudo. A análise dos dados evidenciou, por um lado, que a diatopia responde em grande parte pela diversidade de formas, e, por outro lado, que há uma presença significativa de variantes, no mínimo quatro, para os elementos da fauna alvos do estudo. Entre as variantes documentadas, destaca-se praga, como uma forma particular das mesorregiões Norte e Oeste Maranhense.

PALAVRAS-CHAVE: Dialetologia/Geolinguística. Sociolinguística. Léxico da fauna maranhense. ALiMA.

ABSTRACT: The present work focuses on the denominative variation concerning the fauna lexicon in Maranhão, more particularly the variations referring to the black vulture, opossum and mosquito forms, based on the corpus constituted for the elaboration of the Maranhão

\footnotetext{
* Graduado em Letras pela Universidade Federal do Maranhão (UFMA) e Mestrando do Programa de Pós-graduação em Letras (PGLetras), da Universidade Federal do Maranhão. São Luís - MA. E-mail: Castro.gabriel19@outlook.com

** Doutora em Linguística pela Universidade Federal de Alagoas (UFAL), Professora Permanente do Programa de Pós-Graduação em Letras (PGLetras), da Universidade Federal do Maranhão (UFMA). São Luís - MA. E-mail: conciufma@gmail.com.
}

Revista Moara, n. 55, jan-jul 2020 ISSN: 0104-0944

Recebido em 25/03/2020

Avaliado em 05/05/2020 
Linguistic Atlas (ALiMA). This study aims to examine the diatopic distribution of variants for these forms, in the state, and to investigate which extralinguistic factors condition this variation. The theoretical-methodological assumptions of Geolinguistics/Dialetology (FERREIRA; CARDOSO (1994) and CARDOSO (2010)), Sociolinguistics (CALLOU (2010)) and Lexicology (BIDERMAN (2001) and KRIEGER (2006 e 2014)) support the study. The analysis of the data showed, on the one hand, that diatopia is largely responsible for the diversity of forms, and, on the other hand, that there is a significant presence of variants, at least four, for the fauna elements targeted by the study. Among the documented variants, praga stands out, as a particular form of the Maranhão's North and West Mesoregions.

KEYWORDS: Dialetology/Geolinguistic. Sociolinguistic. Fauna lexicon in Maranhão. ALiMa

\section{Introdução}

As palavras que compõem o amplo repertório de uma língua, disponíveis aos falantes para serem usadas conforme sua necessidade de expressão, representam o léxico de uma língua. Segundo Krieger (2006, p. 159), o léxico é, dentre os outro níveis da língua, o "componente [...] que ocupa um lugar central nas línguas", sendo, por isso, objeto de estudo das mais diversas correntes linguísticas, além de ser, ao menos temporalmente, o que mais permite a observação da variação e, consequentemente, da mudança linguística, justamente por se caracterizar como um sistema instável, aberto e flexível. Dessa forma, há sempre palavras que deixam de ser usadas, caindo, portanto, em desuso; outras sendo criadas (os neologismos) e outras, ainda, ressignificando-se.

Biderman (2001, p. 13) afirma que "O léxico de uma língua natural constitui uma forma de registrar o conhecimento do universo.", evidenciando, portanto, a forma particular como o ser humano observa e classifica as coisas ao seu redor, e como categoriza sua experiência. Nesse sentido, o registro de nosso conhecimento acerca do universo e de nossa vivência se faz por meio de unidades verbais denominadas palavras, unidades basilares do léxico que são, de fato, a representação linguística da categorização de nossa experiência. É, pois, esse processo de nomeação, necessidade intrínseca ao ser humano, que gerou/gera o léxico das línguas (BIDERMAN, 2001). 
Seguindo essas ideias, este estudo, recorte de uma pesquisa mais ampla ${ }^{1}$, tem por objetivo investigar, com base no corpus constituído para a elaboração do Atlas Linguístico do Maranhão (ALiMA), a variação lexical concernente a três entidades da fauna: urubu, gamba e muriçoca. Com o suporte da Geolinguística/Dialetologia e da Sociolinguística, propomo-nos a analisar a variação em uma perspectiva em que o espacial e o sociocultural se entrecruzam.

Analisar fenômenos lexicais com dados de natureza geolinguística nos possibilita observar a língua em seu uso real, em seu contexto de produção, tendo em vista que parte significativa das palavras de que lançamos mão em nosso dia a dia não se encontram registradas nos dicionários gerais da língua. Assim, pretendemos com este estudo contribuir para lançar luz sobre a variação lexical concernente à fauna no estado do Maranhão, por meio de uma amostra das respostas dadas a três questões do Questionário Semântico-Lexical - QSL, adotado pelo ALiMA, aquelas que recobrem, respectivamente, os seguintes conceitos: "ave preta que come animal morto, podre"; "bicho que solta um cheiro ruim quando se sente ameaçado" e "inseto pequeno, de perninhas compridas, que canta no ouvido das pessoas, de noite".

\section{Os atlas linguísticos}

Os esforços que vêm sendo empregados para a construção de um atlas nacional, que descreva a realidade linguística do Brasil, ganharam corpo em 1958 com Antenor Nascentes, com a publicação da obra Bases para a elaboração do atlas linguístico do Brasil. Nessa obra, Nascentes detalhou os procedimentos necessários para que se pudesse pensar em realizar um empreendimento dessa natureza e grandiosidade. Porém, só em 2014 são publicados os dois primeiros volumes do Atlas Linguístico do Brasil (ALiB), com dados apenas de 25 capitais, entre as quais não se incluem o Distrito Federal, devido ao "fato de ter população proveniente ou descendente de diversos pontos do país" (CARDOSO et al., 2013, p. 38), e Palmas, "cidade ainda em formação, sem habitantes nela nascidos" (CARDOSO et al., 2013, p. 38).

\footnotetext{
${ }^{1}$ Recorte da pesquisa intitulada Elementos da fauna no português falado no Maranhão: um estudo com base no corpus do ALiMA, financiada pelo Programa Foco Acadêmico/ UFMA, modalidade - Iniciação Científica, vigência - agosto de 2017 a julho de 2018.
} 
De menor alcance que o altas nacional, há de se reconhecer a necessidade de construção de atlas estaduais e regionais, para um conhecimento mais acurado da realidade linguístico-cultural de cada área do País, pois, como destacam Ferreira e Cardoso (1994, p. 12),

[...] os falantes de uma mesma língua, mas de regiões distintas, têm características linguísticas diversificadas e se pertencem a uma mesma região também não falam da mesma maneira tendo em vista os diferentes estratos sociais e as circunstâncias diversas de comunicação.

Convém, contudo, aclarar que a necessidade de elaboração de atlas regionais e estaduais já ganhara espaço na publicação de Nascentes (1958), que enfatizava a importância de se produzirem também atlas regionais que completariam as lacunas deixadas pelo atlas nacional, uma vez que este não capturaria todas as particularidades e especificidades presentes em cada estado ou mesmo região, em virtude da vastidão do Brasil, que, à época, como destaca Nascentes (1958, p.7), era um país “[...] pobre e sem fáceis vias de comunicação.”.

Atendendo ao chamado de Nascentes e, após a elaboração e publicação do primeiro atlas linguístico no Brasil (entre 1960 e 1963), o Atlas prévio dos falares baianos (APFB), de Nelson Rossi e coautoria de Dinah Isensee e Carlota Ferreira, a geografia linguística brasileira se vai, paulatinamente, a partir da segunda metade da década de 1970, pontilhando de atlas, estaduais e regionais, muitos deles impulsionados pela retomada do projeto de elaboração do atlas nacional, em 1996 (CARDOSO, 2010).

É justamente motivado pelo trabalho do ALiB, e na esteira desse projeto, que surge o Projeto Atlas Linguístico do Maranhão, objetivando, com base numa rede de 16 pontos linguísticos que recobrem as cinco mesorregiões do Estado, investigar mais densamente a realidade maranhense, para identificar fenômenos, nos diferentes níveis de análise, que caracterizam diferenciações ou definem a unidade linguística no Estado (RAMOS et al. 2005). 


\section{A rede de pontos linguísticos do ALiMA e os informantes}

Este estudo considera todos os municípios que fazem parte da rede de pontos linguísticos do Projeto ALiMA, como apresentado no Quadro 1, a seguir:

Quadro 1 - Rede de pontos linguísticos do Projeto ALiMA

\begin{tabular}{|c|c|c|c|}
\hline MESORREGIÃO & MICRORREGIÃO & MUNICÍPIO & $\begin{array}{l}\text { NÚMERO DA } \\
\text { LOCALIDADE }\end{array}$ \\
\hline \multirow{3}{*}{ NORTE } & \multirow{2}{*}{$\begin{array}{c}\text { Aglomeração Urbana de } \\
\text { São Luís }\end{array}$} & São Luís & MA 01 \\
\hline & & Raposa & MA 02 \\
\hline & Baixada Maranhense & Pinheiro & MA 03 \\
\hline \multirow{2}{*}{ CENTRO } & Médio Mearim & Bacabal & MA 16 \\
\hline & Alto Mearim e Grajaú & Tuntum & MA 18 \\
\hline \multirow{3}{*}{ OESTE } & \multirow{2}{*}{ Gurupi } & Carutapera & MA 05 \\
\hline & & Turiaçu & MA 04 \\
\hline & Imperatriz & Imperatriz & MA 07 \\
\hline MESORREGIÃO & MICRORREGIÃO & MUNICÍPIO & $\begin{array}{l}\text { NÚMERO DA } \\
\text { LOCALIDADE }\end{array}$ \\
\hline \multirow{5}{*}{ LESTE } & Chapadinha & Brejo & MA 13 \\
\hline & Caxias & Caxias & MA 12 \\
\hline & Codó & Codó & MA 17 \\
\hline & $\begin{array}{c}\text { Chapadas do Alto } \\
\text { Itapecuru }\end{array}$ & $\begin{array}{c}\text { São João dos } \\
\text { Patos }\end{array}$ & MA 11 \\
\hline & $\begin{array}{c}\text { Baixo Parnaíba } \\
\text { Maranhense }\end{array}$ & Araioses & MA 14 \\
\hline
\end{tabular}




\begin{tabular}{|c|c|c|c|}
\hline \multirow{2}{*}{ SUL } & Porto Franco & Carolina & MA 08 \\
\cline { 2 - 4 } & \multirow{2}{*}{ Gerais de Balsas } & Alto Parnaíba & MA 10 \\
\cline { 3 - 4 } & & Balsas & MA 09 \\
\hline
\end{tabular}

Fonte: ALiMA.

Considerando a natureza das pesquisas dialetais e geolinguísticas contemporâneas, a coleta de dados para elaboração de atlas modernos, principalmente daqueles da chamada última geração, os pluridimensionais, orienta-se tanto pela perspectiva do espaço físico, geográfico, como pela perspectiva do espaço social (CALLOU, 2010). Assim, os informantes selecionados devem atender a critérios rigorosos de seleção, para que, de fato, possam ser representativos dos espaços geográfico e social em que se inserem. Devem, pois, ser naturais da localidade investigada, não devendo dela ter-se afastado por mais de um terço de sua vida, e não podem, ainda, ter emprego ou algum tipo de ocupação que demande afastamento do município por longos períodos. Seus pais devem ser, preferencialmente, naturais da mesma localidade.

Com base nesses critérios, o Projeto ALiMA selecionou quatro informantes por localidade, sendo eles distribuídos igualmente entre os dois sexos, masculino e feminino, e duas faixas etárias, faixa I, de 18 a 30 anos, e faixa II, de 50 a 65 anos. Apenas na capital, São Luís, onde são considerados dois níveis de escolaridade - Ensino Fundamental incompleto (até o sétimo ano) e Ensino Superior (completo) - são selecionados, ao todo, oito informantes, dos quais quatro têm o nível universitário. Nas demais localidades, todos os sujeitos devem ter apenas o Ensino Fundamental incompleto.

Para este estudo, utilizamos o corpus do atlas estadual, que é constituído de dados de fala de 68 sujeitos. Convém, contudo, assinalar que nosso estudo considerou um total de 67 sujeitos, tendo em vista que, quando da realização da pesquisa mais ampla, da qual fazemos este recorte, ainda estava em curso, no âmbito do Projeto ALiMA, a coleta de dados da informante 2 do município de Raposa. 


\section{Urubus, gambás e muriçocas: um recorte da fauna maranhense}

Conforme explanado anteriormente, selecionamos três questões do QSL, a fim de apresentar um recorte da variação lexical concernente ao campo semântico fauna. Para melhor visualização dos resultados, apresentamos a análise e discussão dos dados por questão.

A questão 53, que apura a variação lexical concernente à entidade da fauna descrita como "ave preta que come animal morto, podre", apresentou cinco variantes urubu, abutre, corvo, xengo e azalento -, sendo a forma urubu predominante em todos os pontos investigados, usada, portanto, por todos os informantes, o que equivale a 67 registros, de um total de 74 respostas $^{2}$.

As outras denominações, com menor número de ocorrências que urubu, podem ser observadas no Gráfico 1, a seguir.

Gráfico 1 - Distribuição em porcentagem das denominações concernentes à questão 53

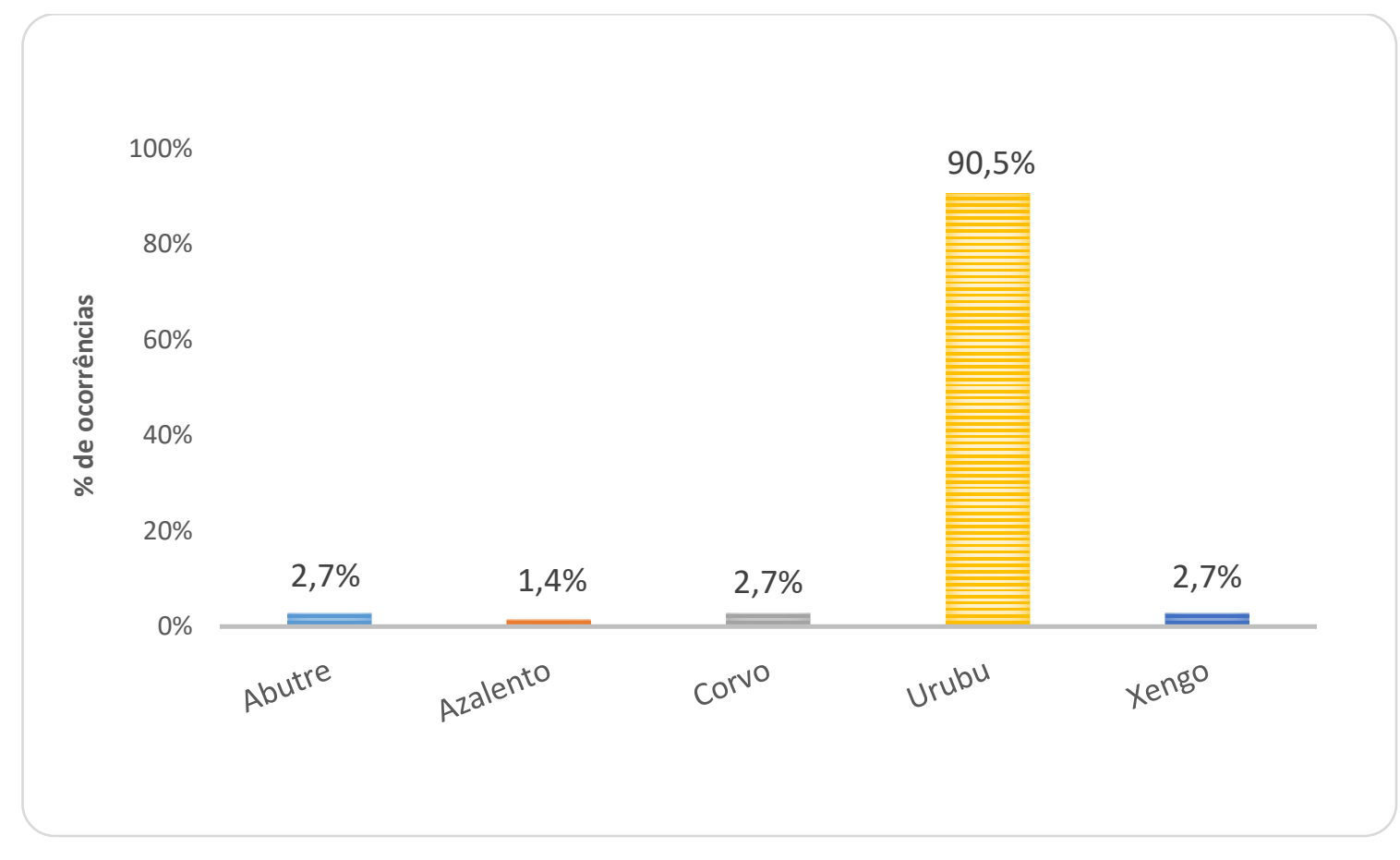

Fonte: Os autores.

\footnotetext{
${ }^{2}$ Convém ressaltar que, durante a aplicação do QSL, os informantes são estimulados a declarar todas as denominações que conhecem para o conceito que lhes é apresentado. Isso leva, normalmente, à obtenção de mais de uma resposta por informante.
} 
Dessas outras denominações, para abutre, que, de acordo com o dicionário Aurélio (FERREIRA, 1999), é uma designação imprópria dada aos urubus brasileiros, contabilizamos duas ocorrências, uma em São Luís e outra em Codó. Ambas foram registradas entre homens da faixa etária II. Também com duas ocorrências, temos corvo (uma ocorrência em Pinheiro, homem, faixa etária I, e uma em Caxias, mulher, faixa etária II) e xengo, registrado apenas entre as mulheres. O item lexical corvo também é registrado no Aurélio (FERREIRA, 1999) como um brasileirismo usado de forma imprópria como variante de $u r u b u$.

A forma xengo encontra-se registrada no Dicionário da língua portuguesa, de Cândido Figueiredo (1949), e no Dicionário da língua portuguesa da Academia Brasileira de Letras, elaborado por Antenor Nascentes (1988), ambas as obras consideram xengo como um brasileirismo, com o significado de boa sorte, felicidade. Como sinônimo de urubu e grafado com “ch”, chengo, encontramos a forma em questão no Pequeno dicionário de termos e expressões populares maranhenses, de José Ribamar Martins (2003, p. 60). Optamos por grafá-la com "x", seguindo a orientação de Luft (2002), que recomenda grafar com “x”, e não "ch", palavras de etimologia ignorada.

Coletamos, ainda, a forma azalento (com apenas uma ocorrência em Codó, na faixa etária I, mulher), que entendemos trata-se de um caso de lambdacismo, isto é, a troca de /r/ por /l/ - azarento > azalento. Vale ressaltar que ao urubu é atribuída, geralmente, uma carga semântica negativa. Em Inácio Filho (2001, p. 320), urubu aparece como "ave de azar".

É interessante observar, como destaca Cascudo (2000, p. 711), a oposição de carga semântica presente nessa ave: por vezes, o urubu é visto como símbolo de azar, mau agouro, falta de sorte; em outros momentos, no âmbito do folclore, por exemplo, é tido como uma criatura simpática. É, ainda, fato consabido que o mascote do maior time de futebol do Brasil - o Flamengo - é o urubu, em função da boa sorte que o animal trouxe para o time em dada ocasião.

Para a questão 60, que apura a variação denominativa concernente à entidade da fauna descrita como "bicho que solta um cheiro ruim quando se sente ameaçado", registramos um total de quatro variantes, sendo a mais produtiva a forma padrão, gambá, com um total de 45 ocorrências, representando 78,9\% dos casos, sendo assim 
predominante em quase todas as localidades investigadas. No entanto, em Codó, registramos um alto índice de ausência de respostas, tendo em vista que, dentre os quatro informantes desse município, dois (50\%), ambos da faixa etária I, declararam, de imediato, não lembrar o nome de tal animal, e um (25\%), faixa etária II, apresentou, inicialmente, variantes léxicas inadequadas (caititu e guaxinim), isto é, que não correspondem ao conceito que lhe foi apresentado, e, em seguida, ao ser solicitada a descrever os animais que citou, declarou que há vários bichos que soltam um cheiro ruim: há esse a que nos referimos e que ela sabe da existência, mas o nome não lhe veio à memória naquele momento; há o guaxinim e outros mais que não chegou a nomear.

Essa ausência de respostas e as respostas inadequadas também nos dizem muito acerca da realidade linguístico-cultural de uma comunidade: por um lado, podem sinalizar que o referente solicitado já não faz parte do universo dos falantes, ou seja, de seu conhecimento de mundo e, por outro lado, podem pôr em evidência que os falantes não lembram como se denomina esse referente ou mesmo desconhecem sua denominação ${ }^{3}$.

O Gráfico 2, a seguir, apresenta a distribuição das variantes lexicais registradas.

\section{Gráfico 2 - Distribuição em porcentagem das denominações concernentes à questão 60}

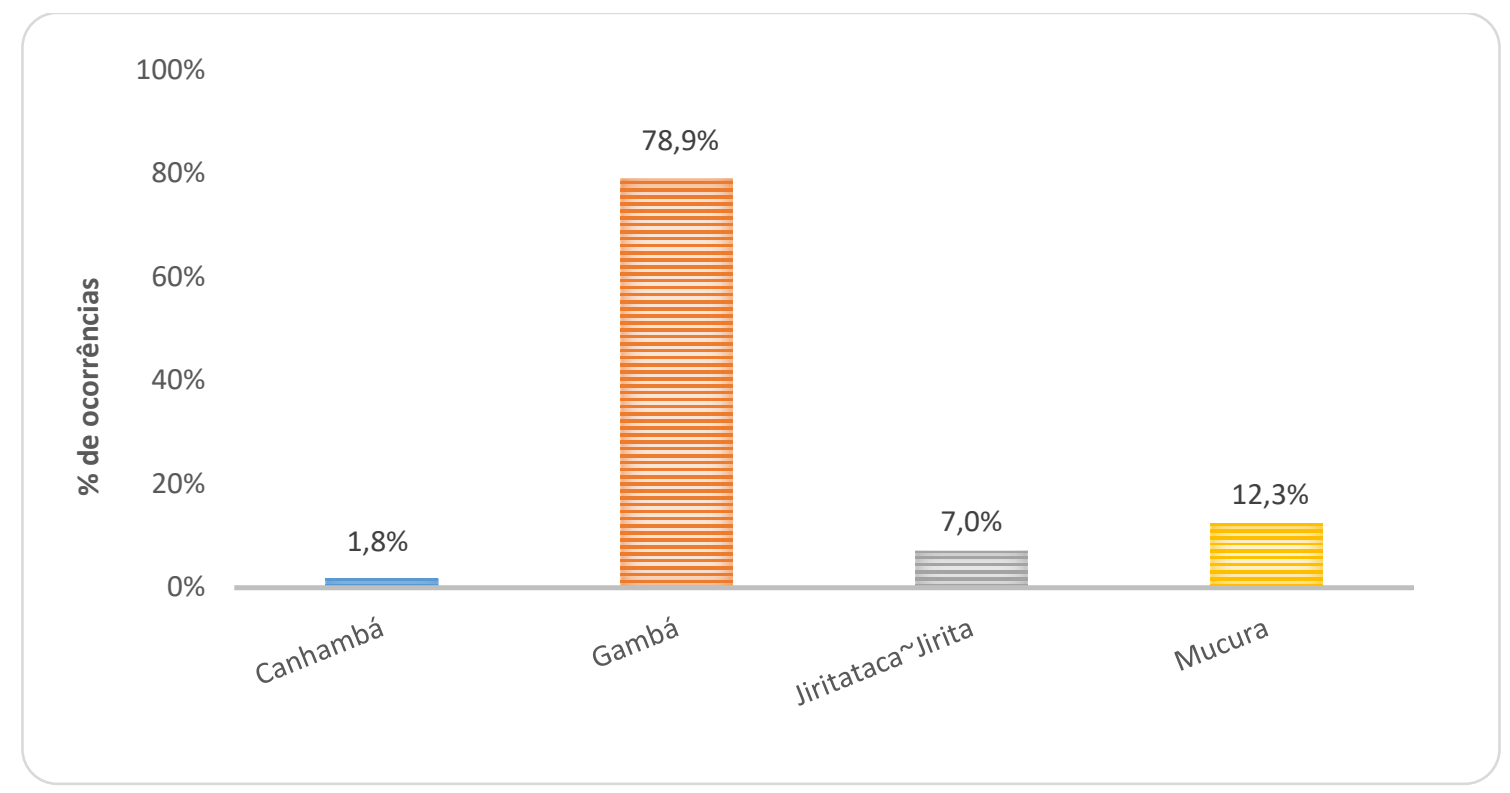

Fonte: Os autores.

\footnotetext{
${ }^{3}$ Buscando lançar mais luzes sobre os resultados de Codó, consultamos outros codoenses: a jovem, faixa etária I, declarou que conhece o animal em questão e que o denomina mucura; a senhora, faixa etária II, assinalou que, atualmente, o gambá aparece mais nos povoados de Codó. Vale destacar que os quatro codoenses entrevistados pelo ALiMA são todos residentes na sede do município.
} 
A forma canhambá foi documentada apenas no município de Bacabal, com uma única ocorrência (homem, da faixa etária II). Na Poranduba maranhense, encontramos a forma maritataca ou cangambá com a seguinte definição: "espécie de foinha pequena, branca, malhada de preto e rabo felpudo. Sendo atacada e algumas vezes antes de o ser solta uma porção de urina tão hedionda, que todo o vivente foge para se livrar do fedor [...]"4. (MARANHÃO, 1946, p. 167). O registro da Poranduba nos leva a inferir que canhambá é, possivelmente, uma variante fonética de cangambá.

Jiritataca e sua forma reduzida jirita tiveram quatro ocorrências, distribuídas entre Bacabal (duas realizações), Brejo e Codó (com uma realização por localidade). Com relação à forma plena, comungamos com a ideia de Pereira (2013), que, respaldado em Cunha (1989), defende que esta forma é uma variante da forma indígena maritataca, encontrada, como vimos, na Poranduba maranhense.

Mucura foi a segunda denominação mais produtiva, com um total de sete ocorrências, distribuídas entre os municípios de Raposa, Caxias, Turiaçu, Tuntum e Araioses. Vale ressaltar que, no dicionário Houaiss (HOUAISS; VILLAR, 2001, p. 1973), encontramos o seguinte verbete: “1 mucura s.f. [...] 1 MASTZOO AMAZ m.q. GAMBÁ (designação comum) [...] ETIM MASTZOO tupi mu'kura 'gambá' [...]”. A título de ilustração, é interessante observar como uma informante de Tuntum descreve a mucura:

INQ. - Como se chama o bicho que solta um cheiro ruim quando se sente ameaçado?

INF. - Mucura?

INQ. - Como é a mucura?

INF. - é um bichinhu assim, é um roedôzinho que parece com um ratinhu ele solta um cheru ruim. Quando eles se sente ameaçado eles solta um cheru ruim mehmo.

INQ. - E a senhora conhece outro além da mucura que também solte um cheiro ruim?

INF. - Gambá, mas o gambá é do mato mehmo.

INQ. - E a mucura?

INF. - Ela dá em casa. De vez em quando ela vem pra comê galinha nos puleru. (Bacabal - MA18, mulher, faixa etária II).

\footnotetext{
${ }^{4}$ Optamos pela não atualização da ortografia.
} 
Com relação aos fatores idade, sexo e localidade, constatamos que não se mostraram relevantes.

Muriçoca foi a denominação mais produtiva para "o inseto pequeno, de perninhas compridas, que canta no ouvido das pessoas, de noite", objeto de estudo da questão 76, com 60 ocorrências, distribuídas entre todas as mesorregiões e quase todos os pontos linguísticos, sem condicionamento dos fatores extralinguísticos. A questão apresentou cinco variantes que, somadas, representam 98 ocorrências. Sua distribuição encontra-se exposta no Gráfico 3, a seguir.

Gráfico 3 - Distribuição em porcentagem das denominações concernentes à questão 76

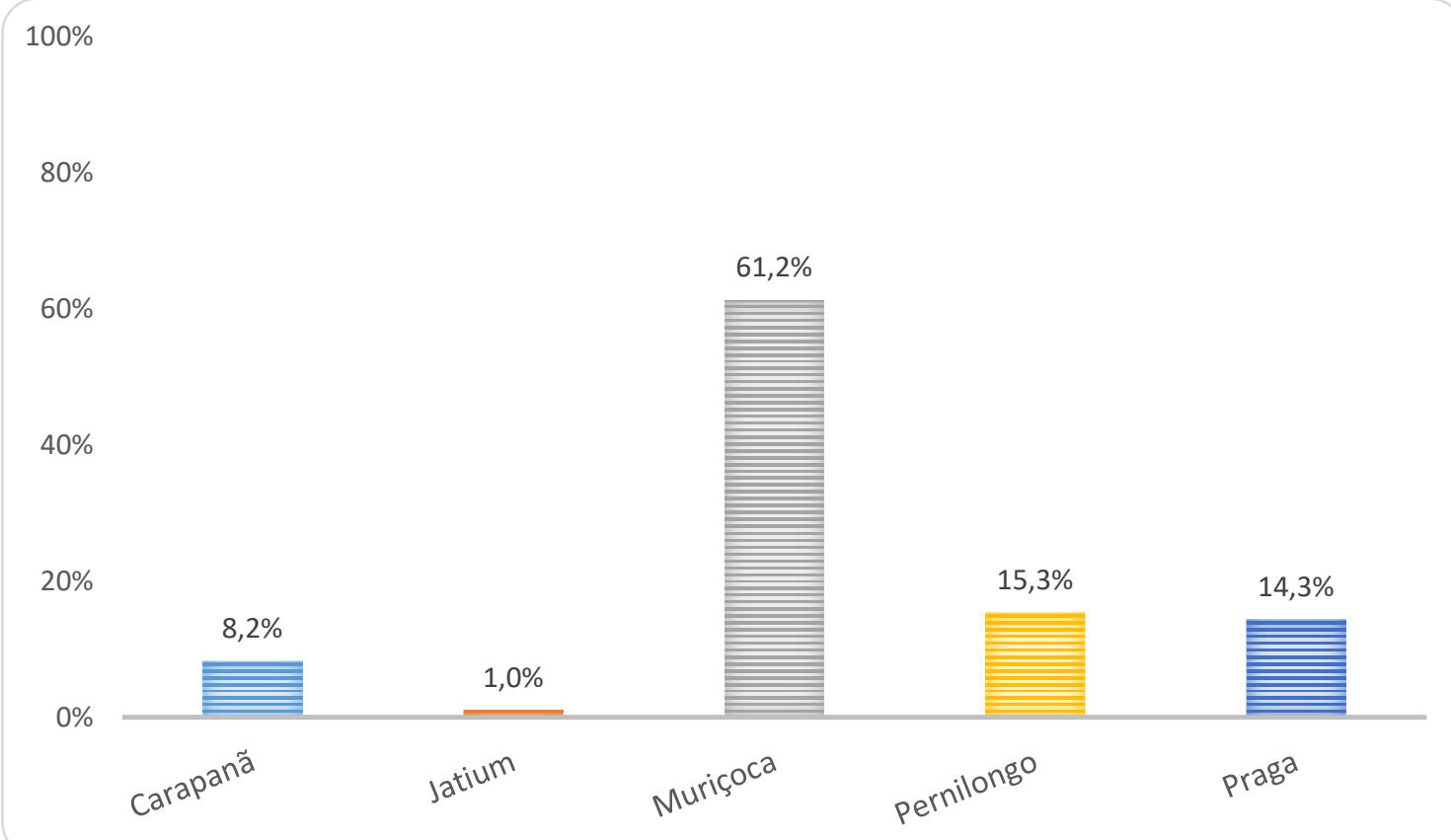

Fonte: Os autores.

Como observamos no Gráfico 3, a questão 76 apresentou cinco variantes, das quais jatium foi a menos produtiva, com apenas uma ocorrência. De acordo com o Michaelis (WEISZFLÖG, 1998, p. 1157), jatium é uma variante de inhatium, mosquito, pernilongo.

Carapanã, por sua vez, apresentou oito ocorrências distribuídas entre Carutapera (três registros), Pinheiro (dois registros), Turiaçu (um registro), Bacabal (um registro) e Codó (um registro), não sendo documentada apenas na mesorregião Sul Maranhense. Dessas oito ocorrências, sete foram registradas entre os homens. A única realização Revista Moara, n. 55, jan-jul 2020 ISSN: 0104-0944 
entre as mulheres foi documentada em Carutapera, na faixa etária I; a carutaperense da faixa etária II não empregou a variante em questão e declarou não lembrar como se denomina o inseto objeto da questão. Esse resultado evidencia, no município, uma tendência a um condicionamento diassexual. As demais variantes - muriçoca, pernilongo e praga -, por sua vez, distribuem-se de forma mais ou menos equitativa entre os sexos.

Ainda com relação à variante carapanã, é interessante notar o condicionamento do fator diatópico, com Carutapera respondendo por 37,5\% dos usos. Vale destacar que Carutapera se situa no extremo Oeste maranhense, fronteando com o Pará, estado da região Norte, onde a forma carapanã é predominante.

Pernilongo, por sua vez, registrou 15 ocorrências, incluindo-se nesse total as variantes fonéticas pernalonga, pernulongu e pernolongu, não apresentado, contudo, condicionamento pelos fatores extralinguísticos selecionados para este estudo.

Praga, com 14 ocorrências, concentra-se nas mesorregiões Norte e Oeste Maranhense, distribuindo-se entre cinco dos 16 municípios que compõem a rede de pontos linguísticos do ALiMA, como evidencia a carta linguística apresentada a seguir.

Essa variante, de acordo com o Michaelis (WEISZFLÖG, 1998, p. 1679), é um regionalismo do Norte e do Nordeste, sendo "[...] Designação genérica de mosquitos hematófagos: carapanã, muriçoca, pium etc.”. Vieira Filho, em sua obra A linguagem popular do Maranhão, cuja primeira edição é de 1953, registra a forma praga, como designação de um "Gênero de mosquito cullex que no inverno invade a cidade." (VIEIRA FILHO, 1979, p. 81). Em se tratando dessa variante, os fatores sociais sexo e faixa etária não foram relevantes. A seguir, na figura 1, observamos a distribuição das formas por ponto linguístico no Maranhão. 


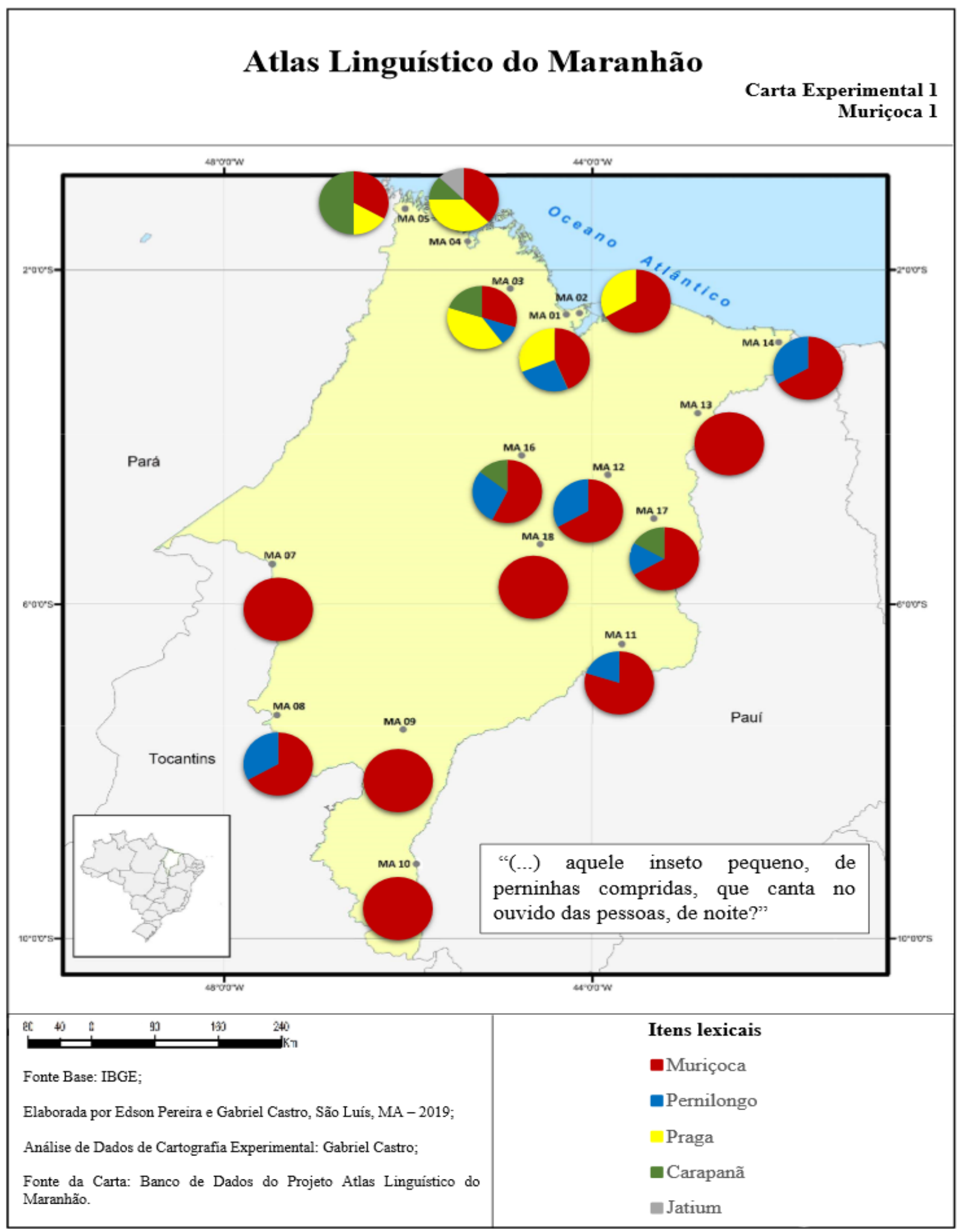

Revista Moara, n. 55, jan-jul 2020 ISSN: 0104-0944 


\section{Considerações finais}

Como resultado do exame da variação lexical no âmbito da fauna no Maranhão, mais particularmente no que diz respeito às entidades urubu, gambá e muriçoca, é possível assinalar alguns pontos que consideramos relevantes:

(i) A variação se evidenciou como mais geográfica que sociocultural, a exemplo do que mostram os dados relativos à questão 76, com a forma praga concentrando-se no eixo Norte-Oeste; carapanã, na porção Centro-Oeste; e muriçoca, com realizações em todo o Estado, mas com predominância no eixo Centro-Sul.

(ii) Com relação às denominações para $u r u b u$, foram contabilizadas cinco variantes, das quais duas - abutre e corvo - ambas com o mesmo percentual de ocorrência $(2,7 \%)$, são consideradas em dicionários gerais da língua, a exemplo de Ferreira (1999), como denominações impróprias dadas aos urubus, no País. Isso ratifica a ideia de que o dicionário não consegue capturar toda a variedade existente numa língua, limitando-se, como assinala Rey (1970 apud KRIEGER, 2014, p. 326), “[...] a nos dar uma imagem do léxico".

(iii) No que tange à questão 60, destacamos que esta apresentou o menor número de variantes, sendo a forma gambá predominante no Estado.

(iv) Com relação à questão 76, que apresentou cinco variantes - muriçoca, pernilongo, praga, carapanã e jatium -, evidenciamos que o fator sexo tende a condicionar o emprego da forma carapanã, majoritária entre os homens.

Finalmente, é importante ressaltar a contribuição dos atlas linguísticos para um conhecimento mais amplo do léxico da língua portuguesa, já que estes reúnem dados autênticos da língua em uso, nos vastos corpora constituídos para sua elaboração. Assim, os atlas contribuem de forma significativa para o registro de nosso patrimônio imaterial, o léxico. 


\section{REFERÊNCIAS}

BIDERMAN, Maria Tereza Camargo. As ciências do léxico. In: OLIVEIRA, Maria Pinto Pires de; ISQUERDO, Aparecida Negri. (org.). As ciências do léxico: lexicologia, lexicografia, terminologia. 2. ed. Campo Grande, MS: Ed. UFMS, 2001, p. 13-22.

CALLOU, Dinah. Quando dialetologia e sociolinguística se encontram. Estudos Linguísticos e Literários, Salvador, n. 41, p. 29-48, jan./jun. 2010.

CARDOSO, Suzana Alice Marcelino. Geolinguística: tradição e modernidade. São Paulo: Parábola Editorial, 2010.

CARDOSO, Suzana Alice Marcelino et al. (org.). Documentos 4: Projeto Atlas Linguístico do Brasil. Salvador: Vento Leste, 2013.

CASCUDO, Luís da Câmara. Dicionário do folclore brasileiro. 9. ed. rev., atual. e il. São Paulo: Global, 2000.

CUNHA, Antônio Geraldo da. Dicionário histórico das palavras portuguesas de origem tupi. 5. ed. São Paulo: Melhoramentos, 1989.

FERREIRA, Aurélio Buarque de Holanda. Novo Aurélio século XXI: o dicionário da língua portuguesa. Rio de Janeiro: Nova Fronteira, 1999.

FERREIRA, Carlota; CARDOSO, Suzana Alice. A dialetologia no Brasil. São Paulo: Contexto, 1994.

FIGUEIREDO, Candido de. Dicionário da língua portuguesa. 14 ed. Lisboa: Livraria Bertrand; Rio de Janeiro: W. M. Jackson, INC, 1949. v. 2.

HOUAISS, Antônio e Villar. Mauro de Salles. Dicionário Houaiss da língua portuguesa. Rio de Janeiro: Editora Objetiva, 2001.

INÁCIO FILHO, José. Vocabulário de termos populares do Ceará: etimologia e tradições. Fortaleza: Edições Livros Técnicos, 2001.

KRIEGER, Maria da Graça. Lexicografia: o léxico no dicionário. In: SEABRA, Maria Cândida Trindade Costa de (org.). O léxico em estudo. Belo Horizonte: Faculdade de Letras da UFMG, 2006, p. 157-171.

KRIEGER, Maria da Graça. Heterogeneidade e dinamismo do léxico: impactos sobre a lexicografia. Confluência, Rio de Janeiro, n. 46, p. 323-334, jan./jun. 2014. Disponível em: http://llp.bibliopolis.info/confluencia/rc/index.php/rc/article/view/22. Acesso em: 26 jan./2019.

LUFT, Celso Pedro. Grande manual de ortografia globo. 2. ed. rev. e atual.. São Paulo: Globo, 2002. 
MARANHÃO, Francisco de Nossa Senhora dos Prazeres. Poranduba maranhense. Separata de: Revista de Geografia e História do Maranhão. São Luís, dez. 1946.

MARTINS, José Ribamar. Pequeno dicionário de termos e expressões populares maranhenses. Brasília, 2003.

NASCENTES, A. Bases para a elaboração do Atlas Lingüístico do Brasil. Rio de Janeiro: MEC: Casa de Rui Barbosa, 1958. v. I.

NASCENTES, A. Dicionário da língua portuguesa da Academia Brasileira de Letras. Rio de Janeiro: Bloch Ed., 1988.

PEREIRA, Edson Lemos. Tupinismos no português falado no Maranhão: elementos da fauna documentados na obra Poranduba maranhense e no Atlas Linguístico do Maranhão - ALiMA. 2013. 79 f. Monografia (Curso de Letras) - Departamento de Letras, Universidade Federal do Maranhão, São Luís, 2013.

RAMOS, Conceição de Maria de Araujo, et al. O atlas linguístico do Maranhão: os caminhos do português falado no Maranhão. In: AGUILERA, Vanderci de Andrade. (org.). A geolinguiística no Brasil: trilhas seguidas, caminhos a percorrer. Londrina: Eduel, 2005. p. 251-284.

VIEIRA FILHO, Domingos. A linguagem popular do Maranhão. 3. ed. aum. São Luís: [s.n.], 1979.

WEISZFLÖG, Walter. Michaelis: moderno dicionário da língua portuguesa. São Paulo: Companhia Melhoramentos, 1998. 